ISSN 2179-6750

\title{
O processo de trabalho e a equipe multidisciplinar: um relato de experiência do Centro Estadual de Atenção Especializada
}

Marcela Quaresma Soares, Carla Fernanda Lisboa Valente Carlos, Jusceli Souza Nogueira Sabino, Daniela Neves Ribeiro, Juliana Aparecida Vieira

\section{Resumo}

O processo de trabalho é entendido como um conjunto de saberes, instrumentos e meios, tendo, como sujeitos, profissionais que se organizam para produzirem serviços de modo a prestarem assistência individual e coletiva para obtenção de produtos e resultados decorrentes de sua prática. $\mathrm{O}$ presente estudo tem como objetivo descrever a experiência vivenciada pela equipe do Centro Estadual de Atenção Especializada da Região de Saúde de Viçosa/MG no aperfeiçoamento do processo de trabalho multiprofissional. Para o desenvolvimento deste estudo foram utilizadas as bases de dados digitais e literatura escrita e coletados dados junto aos profissionais da referida equipe. Quando as atividades do CEAE iniciaram era claro que a forma de desenvolver o trabalho pelos diversos profissionais estava diretamente relacionada às concepções que estes apresentavam sobre o processo saúde-doença quando foram convocados para compor a equipe. A forma de trabalhar era o da "equipe agrupamento", com trabalhadores colocados juntos em um mesmo ambiente, trabalhando de forma individual. Entretanto, através da Educação Permanente em Saúde (EPS) essas concepções sofreram alterações, rearranjos, contribuindo para mudanças no modo de desenvolver suas atividades profissionais, a fim de atender pessoas/grupos/famílias em sua integralidade construindo projetos terapêuticos. Os profissionais precisaram reconhecer que para abordar a complexidade do trabalho em saúde são necessários distintos olhares, saberes e fazeres. Houve diferenças significativas do alcance da integração multiprofissional e das possibilidades de enriquecimento da assistência prestada, de acordo com as circunstâncias em que o trabalho interdisciplinar é posto em ação. Aos poucos foi surgindo um novo modo de trabalhar em equipe, com prevalência do direcionamento pelas tecnologias leves, potencializando o relacionamento entre os profissionais e destes com os usuários. Ocasionando mudanças na forma como se produz e para quem se produz o cuidado, com vistas em construir um novo fazer saúde.

Descritores: Processo de trabalho; Equipe multiprofissional; Cuidado. 